\title{
Systems biology of microbial infection
}

\section{Reinhard Guthke*, Jörg Linde, Franziska Mech and Marc Thilo Figge}

Leibniz Institute for Natural Product Research and Infection Biology - Hans Knöll Institute, Jena, Germany

${ }^{*}$ Correspondence: reinhard.guthke@hki-jena.de

Edited by:

lan Marriott, University of North Carolina at Charlotte, USA

Reviewed by:

lan Marriott, University of North Carolina at Charlotte, USA

This special Systems Biology of Microbial Infection research topic is dedicated to the dynamic modeling and model-driven analysis of microbial infection processes. It aims at describing and analyzing the confrontation of the host with bacterial and fungal pathogens, and at modeling and understanding the interactions of the immune system of humans and animals, with pathogens.

The early stages of the mathematical modeling of infectious diseases were initiated at the beginning of the twentieth century and were based on the population dynamics of epidemics, e.g., to design governmental vaccination policy (Ross, 1911, 1916).

Today, systems biology of microbial infection considers molecular, cellular, and even organismic levels of the pathogen and the host's immune system and is directed toward personalized medicine and theranostics.

The presented papers comprise theoretical and experimental studies. Some contributions present an integrative analysis of genome-wide data from both the host and the pathogen. Other contributions report on spatio-temporal determinations of host-pathogen interactions or the response of the host and pathogenic cells to defined perturbations that simulate infectious conditions.

This research topic is organized in two parts, with the first part consisting of four review articles and the second part consisting of seven original research papers.

\section{PART I: REVIEW ARTICLES}

Horn et al. (2012) review the systems biology of fungal infection, regarding virulence determinants of fungal pathogens, their adhesion and colonization of the host, their metabolism and gene expression patterns during infection, and their interaction with host cell types.

Haas (2012) reviews the regulation of iron uptake from the host and its storage within Aspergillus fumigatus cells as well as the regulation of iron homeostasis and transcriptional regulation under conditions of iron starvation within the pathogen.

Another example of adaptation to a pathogenic lifestyle to the conditions in the host is reviewed by Dandekar et al. (2012). The authors report on recent findings regarding the metabolic modeling of adaptation of Salmonella sp. to nutritional conditions within the host's vacuoles and membrane-bound compartments. Furthermore, the required metabolic conditions during Salmonella infection are compared with those for Listeria and Legionella.
Next, infection arises if the pathogen multiplies and overgrows the normal microbial flora, either at the place of entrance or in deeper tissue layers and organs. This is reviewed by Fuchs et al. (2012) focusing on the bacterial replication of metabolism in Listeria.

\section{PART II: ORIGINAL RESEARCH PAPERS}

The original research papers demonstrate different systems biology approaches to model: (i) host-pathogen interactions, (ii) molecular interaction networks of the pathogen, and (iii) host responses to the microbial infection.

\section{HOST-PATHOGEN INTERACTION}

In the past, most studies have focused on either the side of the pathogen or the host. Tierney et al. (2012) try to overcome this limitation using Next Generation Sequencing (RNA-Seq analysis) to monitor the gene expression of the host and the pathogen simultaneously. They analyze and model the interaction of mouse bone marrow-derived dendritic cells with the pathogenic yeast Candida albicans, and infer a gene regulatory network comprising genes and proteins of both host and pathogen.

Durmuş Tekir et al. (2012) study more than 23,000 protein-protein interactions that characterize the strategies of interaction of the human host with viral, bacterial, and some fungal pathogens utilizing the database pathogen-host-search-interaction-tool (PHISTO).

Binder et al. (2012) modeled the population dynamics of Borrelia burgdorferi using an ordinary differential equation approach taking into account the dissemination of bacteria to different tissues as well as cellular phagocytic activity during the innate immune response. By comparing different model scenarios with experimental data on infected mice, they aim at understanding why an almost cleared population of these bacteria can recover and reach a size that is even larger than the initial population before entering the chronic phase.

Applying an agent-based modeling approach that treats cells as discrete objects in space with dynamic properties, Tokarski et al. (2012) simulated the interactions of conidia of the human-pathogenic fungus $A$. fumigatus with migrating human neutrophils. Based on the analysis of time-lapse microscopy image data, different scenarios of phagocyte migration are explored and evaluated with regard to the clearance efficiency.

\section{MOLECULAR INTERACTION NETWORK OF THE PATHOGEN}

A genome-wide gene regulatory network has been inferred by Altwasser et al. (2012) for C. albicans using a compendium of microarray data by integration of prior knowledge from different 
sources (e.g., transcription factor - target gene and protein-protein interaction data bases) as well as a large number of research papers screened for regulator/target gene interactions relations by an automatic text mining search.

\section{HOST RESPONSE TO MICROBIAL INFECTION}

Monitoring the immune response by flow cytometry for immune cells and cytokine production, Simon et al. (2012) identified and analyzed correlations and decision rules that formulated multidimensional and non-linear relations between the measured data on T-helper-cells and the cytokines GM-CSF, IFN-gamma, IL-2, IL-17, RANKL, and TNF-alpha. The authors found that, in particular, the production of GM-CSF and IL-17 turned out to be highly correlated.

Translational systems biology aims at the integration of omics data and clinical data from individual patients based on the investigation of animal models for therapeutical interventions. Lambeck et al. (2012) analyzed and compared the transcriptome from blood samples of a murine sepsis model together with that of patients from the pediatric intensive care unit.

\section{REFERENCES}

Altwasser, R., Linde, J., Buyko, E., Hahn, U., and Guthke, R. (2012). Genomewide scale-free network inference for Candida albicans. Front. Microbiol. 3:51. doi: 10.3389/fmicb.2012.00051

Binder, S. C., Telschow, A., and MeyerHermann, M. (2012). Population dynamics of Borrelia burgdorferi in Lyme disease. Front. Microbiol. 3:104. doi: 10.3389/fmicb.2012.00104

Dandekar, T., Fieselmann, A., Popp, J., and Hensel, M. (2012). Salmonella enterica: a surprisingly welladapted intracellular lifestyle. Front. Microbiol. 3:164. doi: 10.3389/ fmicb.2012.00164

DurmuşTekir, S., Çakir, T., and Ülgen, K. Ö. (2012). Infection strategies of bacterial and viral pathogens through pathogen-human protein-protein interactions. Front. Microbiol. 3:46. doi: $10.3389 /$ fmicb. 2012.00046
Fuchs, T. M., Eisenreich, W., Kern, T., and Dandekar, T. (2012). Toward a systemic understanding of Listeria monocytogenes metabolism during infection. Front. Microbiol. 3:23. doi: 10.3389/fmicb.2012.00023

Haas, H. (2012). Iron - a key nexus in Front. Microbiol. 3:28. doi: 10.3389/ fmicb.2012.00028

Horn, F., Heinekamp, T., Kniemeyer, O., Pollmächer, J., Valiante, V., and Brakhage,A.A. (2012). Systems biology of fungal infection. Front. Microbiol. 3:108. doi: 10.3389/fmicb.2012.00108

Lambeck, S., Weber, M., Gonnert, F. A., Mrowka, R., and Bauer, M. (2012). Comparison of sepsis-induced transcriptomic changes in a murine model to clinical blood samples identifies common response patterns. Front. Microbiol. 3:284. doi: 10.3389/ fmicb.2012.00284 the virulence of Aspergillus fumigatus.

\section{SUMMARY}

Systems biology of microbial infection aims at the development of testable mathematical and computational models of host-pathogen interactions that have predictive power for diagnosis and therapy by focusing on biomarkers and drug targets. This Research Topic presents a survey on the current state of this field. Some results were already presented at the first International Workshop on the "Systems Biology of Microbial Infection" that was held in 2011 in Jena, Germany, and will be organized in a biennial fashion by the Leibniz Institute for Natural Product Research and Infection Biology - Hans Knöll Institute (HKI), Jena. Today, the field of systems biology of microbial infection is still in its infancy. However, we are convinced that the integration of "omics" approaches with image-based systems biology will strengthen and open new avenues to quantitative modeling of host-pathogen interactions in the future.

\section{ACKNOWLEDGMENT}

The authors acknowledge the excellence graduate school "Jena School for Microbial Communication (JSMC)" for support.

Ross, R. (1911). The Prevention of Malaria London: Murray.

Ross, R. (1916). An application of the theory of probabilities to the study of a priori pathometry. Part I. Proc. $R$. Soc. Lond. A 92, 204-230.

Simon, S., Guthke, R., Kamradt, T., and Frey, O. (2012). Multivariate analysis of flow cytometric data using decision trees. Front. Microbiol. 3:114. doi: 10.3389/fmicb.2012.00114

Tierney, L., Linde, J., Müller, S., Brunke, S., Molina, J. C., Hube, B., Schöck, U., Guthke, R., and Kuchler, K. (2012). An interspecies regulatory network inferred from simultaneous RNA-seq of Candida albicans invading innate immune cells. Front. Microbiol. 3:85 doi: 10.3389/fmicb.2012.00085

Tokarski, C., Hummert, S., Mech, F., Figge, M. T., Germerodt, S., Schroeter, A., and Schuster, S. (2012). Agentbased modeling approach of immune defense against spores of opportunistic human pathogenic fungi. Front. Microbiol. 3:129. doi: 10.3389/ fmicb.2012.00129

Received: 20 July 2012; accepted: 24 August 2012; published online: 12 September 2012. Citation: Guthke R, Linde J, Mech F and Figge MT (2012) Systems biology of microbial infection. Front. Microbio. 3:328. doi: 10.3389/fmicb.2012.00328

This article was submitted to Frontiers in Microbial Immunology, a specialty of Frontiers in Microbiology.

Copyright (c) 2012 Guthke, Linde, Mech and Figge. This is an open-access article distributed under the terms of the Creative Commons Attribution License, which permits use, distribution and reproduction in other forums, provided the original authors and source are credited and subject to any copyright notices concerning any thirdparty graphics etc. 